\title{
Plant and Pest Diagnosis and Identification Through DDIS $^{1}$
}

\author{
J. Xin, L. Buss, C. Harmon, P. Vergot III, M. Frank, and W. Lester ${ }^{2}$
}

\section{Introduction}

Florida's agriculture, horticulture, and natural resources constantly face threats of plant disease, insects, weed problems, and invasive species. Pests and plant diseases are also a threat to market access, natural ecosystems, and our food supply. Florida is a high-risk state for the introduction of numerous invasive species. Reports show that an average of two new invasive species, including arthropods, nematodes, and plant diseases, are discovered in Florida each month. Damages associated with invasive species cost the United States $\$ 120$ billion annually (Pimentel 2005). Given the vulnerabilities and impact to our agricultural and natural resources, early detection of pests and invasive species is essential to prevent these threats from becoming established in Florida. There is a critical need for rapid and accurate diagnoses of economically important insect pests, plant pathogens, and noxious weeds. The latest information technologies make it possible to identify potential plant pests and deliver appropriate management strategies with the assistance of alternative approaches.

Integrated pest management involves the correct and timely identification and control of weeds, insects, and diseases. Pests above threshold levels may lead to decline in the general health of agricultural and horticultural crops, cause structural damage, and threaten human health and safety. If pest problems are left untreated for too long, they may lead to substantial economic loss and human health issues. Although pest management information may be available, accurate identification of the pest, disease, and the host plant is the first step in initiating an integrated pest management program. Accurate and rapid diagnosis can help producers avoid costly mistakes (treating for the wrong pest, applying a fungicide when no fungicide is warranted, etc.). Pest identification and diagnosis can be difficult and often require consultation with a specialist. A common approach is to collect samples and deliver them by mail to a specialist for identification. Regular package delivery methods can take days, leading to delays in pest control recommendations. Sometimes, mailed samples deteriorate during shipment and become unsuitable for diagnosis.

Extension county faculty, state specialists, and faculty of the UF/IFAS Office of Information Technology developed the Distance Diagnostic and Identification System (DDIS) for UF/IFAS Extension. DDIS allows users to submit digital images obtained in the field or after delivery to a local Extension office for rapid diagnosis and identification of pest insects, weeds, diseases, and animals. This system provides a digital image library with associated GPS location,

1. This document is ABE327, one of a series of the Department of Agricultural and Biological Engineering, UF/IFAS Extension. Original publication date July 2002. Revised March 2018. Visit the EDIS website at http://edis.ifas.ufl.edu.

2. J. Xin, senior associate, Office of Information Technology; L. Buss, senior biological scientist, Department of Entomology and Nematology; C. Harmon, senior associate, Plant Pathology Department; P. Vergot III, professor, district director; M. Frank, Extension botanist, University of Florida Herbarium; and W. Lester, Extension agent II, UF/IFAS Extension Hernando County; UF/IFAS Extension, Gainesville, FL 32611.

The use of trade names in this publication is solely for the purpose of providing specific information. UF/IFAS does not guarantee or warranty the products named, and references to them in this publication do not signify our approval to the exclusion of other products of suitable composition.

The Institute of Food and Agricultural Sciences (IFAS) is an Equal Opportunity Institution authorized to provide research, educational information and other services only to individuals and institutions that function with non-discrimination with respect to race, creed, color, religion, age, disability, sex, sexual orientation, marital status, national origin, political opinions or affiliations. For more information on obtaining other UF/IFAS Extension publications, contact your county's UF/IFAS Extension office. 
crop, and pest or disorder data that can be used in future educational programs. DDIS is an effective communication tool for county Extension faculty, state specialists, clinic and lab diagnosticians, and external experts. DDIS provides a way for county Extension faculty to assist their clientele with rapid pest identification and diagnosis.

\section{Typical DDIS Hardware and Camera}

A digital camera is needed to prepare a digital sample. Users may start with a smartphone or a comparable camera. If you are photographing a small object, a macro lens with decent macro capabilities at a magnification ratio of $1: 1$ is recommended. A microscope or stereo microscope with digital image capture capability may be needed for certain samples. Below is a list of devices for DDIS. For the latest DDIS hardware configuration, please visit the DDIS website at http://ddis.ifas.ufl.edu.

- Camera or smartphone (with close-up capability)

- Microscope or stereo microscope

- Microscope illuminator or light

\section{How does the DDIS process work?}

The process of DDIS has four steps: 1) observe a pest, unknown plant, or symptom, 2) capture images through a digital camera with or without the use of a microscope, 3) submit the sample, with the option to revise the sample after initial submission, and 4) await diagnosis by a clinic or specialist. Turnaround time can range from hours to days, depending on the communication with the correct specialist, the quality of the image and associated information, and whether the pest can be diagnosed by images alone.

Data confidentiality and secure diagnosis are important. If a sample is sensitive, mark the sample as "private" so only the sample submitter and receivers can access it. Both the sample submitter and the diagnostician receive notifications of the sample's status via email.

It is critical to prepare an in-focus and comprehensive digital sample. In general, images should include an entire view as well as close-up views of symptoms or diagnostic characteristics that facilitate accurate identification. For example, Figure 1 shows damage to a white fringetree, followed by a closer view of the damage, and then a closeup image of the insect responsible for the damage. In most cases, a successful diagnosis largely depends on the quality of the digital sample, along with a thorough explanation of the issue. Additional guidelines for submitting plant and pest photos are available on the DDIS website: http:// ddis.ifas.ufl.edu. Generally, weed and insect ID is more successful through DDIS than disease symptom diagnosis, which often requires a specimen submitted to a laboratory or specialist.

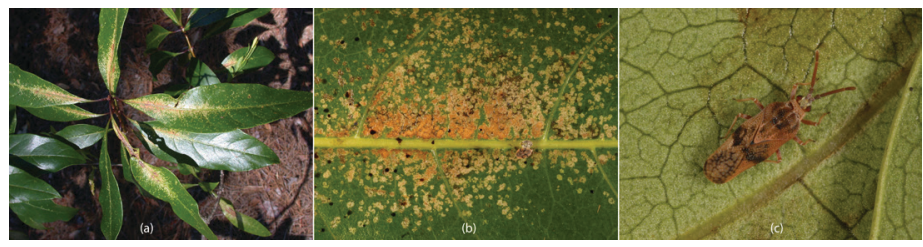

Figure 1. Pictures of damage to leaves of a white fringetree $(a, b)$ caused by the fringetree lace bug (c).

Credits: Eileen Buss (a) and Lyle Buss (b, c), UF/IFAS

In addition, users may send a digital sample to several specialists or clinics for diagnosis simultaneously. For example, a sample can be sent to a pathologist and a physiologist so that they may collaborate on an answer.

\section{DDIS Sample Types and User Roles}

DDIS users may submit digital samples in the following categories to diagnostic clinics or specialists:

- Plant disease

- Insect (plant and non-plant)

- Plant and weed ID

- Mushroom/fungus ID

- Management, physiology, and nutrient

- Livestock

The DDIS system provides different user roles that allow various users to perform distinct tasks assigned to them. Figure 2 shows user roles and interaction among DDIS users. Sample submitters could be:

- UF/IFAS Extension faculty or first detectors with full submission rights,

- Extension clientele with the right to submit samples to UF/IFAS Extension faculty in their county, or

- Clinic-approved users with the right to submit samples to that lab or clinic.

On the specialist side, there are four types of users:

- State specialists at UF/IFAS departments,

- Clinic or laboratory diagnosticians,

- Registered non-UF/IFAS DDIS specialists, and

- External experts referred by DDIS specialists. 


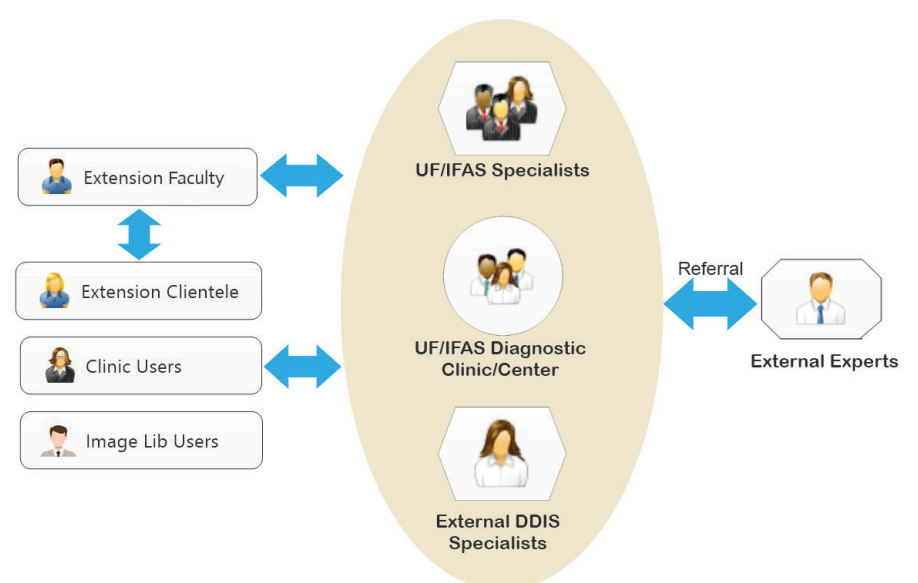

Figure 2. Collaboration among DDIS users and diagnostic clinics or specialists.

Credits: Jiannong Xin, UF/IFAS

\section{DDIS for Extension Clientele}

Extension clientele, such as Master Gardeners, growers, and homeowners, may use DDIS and interact with their local UF/IFAS Extension faculty. Extension clientele may sign up for an account within the Extension Clientele user group on the DDIS website. However, the new account will only be activated after it receives a county faculty member's approval. Authorized Extension clientele may submit a digital sample directly to their UF/IFAS Extension faculty. After a county Extension faculty member receives the sample, he/she may reply to the clientele or forward the sample to appropriate clinics or specialists for diagnosis.

\section{DDIS Mobile}

DDIS also has a mobile web version. Users may observe a symptom, capture a digital sample anywhere using a smartphone camera, and rapidly submit the sample for quick diagnosis. Figure 3 shows the DDIS mobile sample management interface. The mobile version puts the technology at users' fingertips.

\section{Become a DDIS user}

To become a DDIS user, visit the DDIS website (http://ddis. ifas.ufl.edu) and select "Become a user" from the home page. Fill in all required fields and follow the on-screen instructions. Diagnosis service accounts are only provided for Florida residents. It is recommended that new users go through the DDIS "Quick Start" and "How To" tutorials. Users may submit a DDIS sample in three easy steps: 1) sign up as a DDIS user, 2) prepare a digital sample, and 3) submit the sample to specialists or clinics.

\begin{tabular}{|c|c|}
\hline (1) ddis.ifas.ufl.edu/ddisx/logir & $6 \quad \vdots$ \\
\hline (4) DDIS DDIS Mobile & Full Site \\
\hline Submit Sample for Diagnosis & A \\
\hline Plant Disease & 8 \\
\hline Insect (Plant) & 8 \\
\hline Insect (Non-plant) & (2) \\
\hline Plant/Weed & 8 \\
\hline Mushroom/Fungus & 0 \\
\hline Management/Nutrient & 8 \\
\hline Livestock & 0 \\
\hline View My Samples & 8 \\
\hline View Recent Samples & $?$ \\
\hline Search Samples & 8 \\
\hline
\end{tabular}

Figure 3. DDIS mobile application sample management interface. Credits: Jiannong Xin, UF/IFAS

\section{Summary}

Florida's agriculture, horticulture, and natural resources are vulnerable to insects, plant diseases, and invasive species. DDIS was developed to assist UF/IFAS clinics, specialists, Extension faculty, and their clientele in rapid diagnosis and identification of these issues. DDIS provides a secure and effective digital means for pest and plant diagnosis and identification. However, the system is not a replacement for traditional laboratory analysis of many difficult plant, insect, and plant disease samples. DDIS creates an archive of images with associated location, host crop, and pest or disorder data statewide. These archived images form a digital reference library to aid in identification and understanding of plant, insect, and disease management, and to inform Extension personnel and their clients. In summary, DDIS at UF/IFAS:

- Provides a diagnostic system with rapid early detection of unknown plant hosts, pests, plant diseases, and invasive species

- Increases the diagnostic collaboration among county Extension faculty, their clientele, and UF/IFAS state specialists as well as other experts around the world

- Extends diagnostic and identification services to Extension clientele through county faculty

- Archives results in an accessible and dynamic database for research and educational use 


\section{Reference}

Pimentel, D. 2005. "Environmental consequences and economic costs of alien species." Invasive Plants: Ecological and Agricultural Aspects: 269-275. Accessed on February 20, 2018. https://link.springer.com/content/pdf/10.1007/37643-7380-6_17.pdf 